\title{
Seroprevalence and Risk Factors Associated to Avian Chlamydiosis Among Pigeons in Bangladesh: First Known Evidence
}

\author{
Umme Kulsum ${ }^{1}$, Delower Hossain ${ }^{2 *}$, Azizul Hoque ${ }^{3}$, Abdul Ahad ${ }^{1}$, Pankaj Chakraborty $^{4}$ \\ ${ }^{1}$ Department of Microbiology and Veterinary Public Health, Faculty of Veterinary Medicine, Chattogram Veterinary \\ and Animal Sciences University, Chattogram 4225, Bangladesh; ${ }^{2}$ Department of Medicine and Public Health, Faculty \\ of Animal Science and Veterinary Medicine, Sher-e-Bangla Agricultural University, Dhaka 1207, Bangladesh; \\ ${ }^{3}$ Department of Pathology and Parasitology, Faculty of Veterinary Medicine, Chattogram Veterinary and Animal \\ Sciences University, Chattogram 4225, Bangladesh; ${ }^{4}$ Department of Medicine and Surgery, Faculty of Veterinary \\ Medicine, Chattogram Veterinary and Animal Sciences University, Chattogram 4225, Bangladesh.
}

\begin{abstract}
Chlamydia (C.) psittaci is an important zoonotic pathogen that circulates in a wide range of avian species, mammals and humans. A cross-sectional study was conducted based on the seroprevalence of $C$. psittaci in association to the potential risk factors with Chlamydia infection in pigeons to assess their role as source of human Chlamydia infection. A total of 91 samples were screened by Enzyme linked immunosorbent assay (Sandwich-ELISA) to detect C. psittaci antibody (Cps-Ab). The results indicated that, 6 (6.6\%) samples contained C. psittaci antibody (Cps$\mathrm{Ab})$ and the duration of illness and clinical conditions in pigeons had significant influence ( $\mathrm{p}<0.05)$ on Chlamydia seropositivity. In addition, the prevalence of $C$. psittaci antibody was predominant in local pigeons and most of the seropositive pigeons were less than 6 months of age. Based on the presence of antibody against $C$. psittaci the study suggests that, Chlamydia is prevalent among pigeons in the study area. Therefore, the pigeon may be a potential source of human Chlamydia infection in Bangladesh. Moreover, careful initiative is needed to protect it involving community, government and animal protection societies as well as scientists.
\end{abstract}

Keywords | Seroprevalence, ELISA, Chlamydia psittaci, Pigeon, Chattogram

Received | April 21, 2021; Accepted | July 07, 2021; Published | September 25, 2021

*Correspondence | Delower Hossain, Department of Medicine and Public Health, Faculty of Animal Science and Veterinary Medicine, Sher-e-Bangla Agricultural University, Dhaka 1207, Bangladesh; Email: delowervet@sau.edu.bd

Citation | Kulsum U, Hossain D, Hoque A Ahad A, Chakraborty P (2021). Seroprevalence and risk factors associated to avian chlamydiosis among pigeons in Bangladesh: first known evidence. Adv. Anim. Vet. Sci. 9(11): 1869-1875.

DOI | http://dx.doi.org/10.17582/journal.aavs/2021/9.11.1869.1875

ISSN (Online) | 2307-8316; ISSN (Print) | 2309-3331

Copyright $\odot 2021$ Kulsum et al. This is an open access article distributed under the Creative Commons Attribution License, which permits unrestricted use, distribution, and reproduction in any medium, provided the original work is properly cited.

\section{INTRODUCTION}

$C$ Wlamydia is a genus comprised of important zoonotic obligate intracellular bacteria that affect humans and a wide range of animals (Longbottom and Coulter, 2003; Rohde et al., 2010). Chlamydia (C.) psittaci can infect 465 avian species in 30 avian orders, with at least 153 species in the order Psittaciformes (Vanrompay et al., 2007). It is known that pigeons, like many other bird species, have a history of antibodies present against $C$. psittaci (Heddema et al., 2006). Chlamydia infection can cause various diseases in non-human mammals and birds, including conjunctivitis, atypical pneumonia, enteritidis, endocarditis, and even abortion, resulting in serious economic losses (Eidson, 2002; Entrican and Wheelhouse, 2006; Pannekoek et al., 2009; Verminnen and Vanrompay, 2009).

Chlamydia psittaci is a causative agent of psittacosis, a range of systemic diseases in psittacine birds which can be of acute, chronic or subclinical manifestation and represents the most important animal chlamydiosis of zoonotic character (Goellner et al., 2006). Chlamydia psittaci is a bacterium that can be transmitted from pet birds to humans (Johnston et al., 2000). The first case of zoonotic C.psittaci 
from pigeons was described in 1941 (Meyer, 1941).

Chlamydia psittaci can be transmitted to humans by direct contact with animals (cattle, dog, cat, wild boar and so on), avian nasal discharges, infectious avian fecal material or even inhalation of feather dust ( $\mathrm{Ni}$ et al., 2015; Balsamo et al., 2017). Several Chlamydia species can infect humans and are responsible for creating many serious public health problems like atherosclerosis, coronary heart disease, pneumonia and other severe diseases (Wu et al., 2013). Persons at risk include those exposed to pet birds, pigeons and poultry and in specific occupations such as laboratory and wildlife workers (Smith et al., 2005; Doosti and Arshi, 2011). Human infection can result from even brief exposure to the contaminated excretions or secretions of infected birds (Smith et al., 2005). The largest epidemic occurred in 1930 and affected 750-800 individuals in Europe and the United States. During 2003-2014, 112 human cases of psittacosis were reported to the Center for Disease Control and Prevention through the Nationally Notifiable Diseases Surveillance System (CDC, 2016).

Bangladesh has a long historical record of rearing poultry species using the backyard system (Alam et al., 2014). Due to suitable weather and large crop fields along with housing premises, pigeon farming is gaining popularity among the younger generation as a domestically reared bird, producing both income and entertainment in Bangladesh (Asaduzzaman et al., 2009; Gofur, 2020; Parvez et al., 2020). Although, pigeons are considered as the potential sources of several human zoonotic pathogens like avian tuberculosis, chlamydiosis, salmonellosis, avian influenza, velogenic Newcastle disease (ND) and so on in many countries (Cooper, 1997; Haag-Wackernagel, 2006; Morita et al., 1994). The current status of chlamydiosis in pigeons is still anonymous in Bangladesh. There is no published scientific report on Chlamydia infection in Bangladesh to date. Moreover, due to lack of modern facilities, suspected Chlamydia infections in pet birds and animals are still diagnosed by clinical signs and post-mortem lesions in the region. Research based on the seroprevalence study of Chlamydia in pigeons will give benevolent information on the current situation of Chlamydia infection and its prevalence in the study area. The results of the study will be helpful for the government and researchers to give attention on it and aware the people about such important zoonoses. Based on the situation, the present study was designed to elucidate the seroprevalence of $C$. psittaci in the pigeon. A total of 91 sera samples from pigeons have been screened to find out seroprevalence of Chlamydia. Positive samples were compared to collected data to explain the potential risk factors of Chlamydia infection in pigeons of the study area.

\section{MATERIALS AND METHODS}

\section{STUdy AREA}

The present cross-sectional study was conducted in 17 rooftop pigeon farms of the Chattogram district (between $21^{\circ} 54^{\prime}$ and $22^{\circ} 59^{\prime} \mathrm{N}$ and $91^{\circ} 17^{\prime}$ and $92^{\circ} 13^{\prime} \mathrm{E}$ ) of Bangladesh. The samples were collected from different parts of the Chattogram metropolitan area including Pahartali, Patenga, Nasirabad, Khulshi, Foy's Lake, Sholashahar, Dampara and Jalalabad (Figure 1).

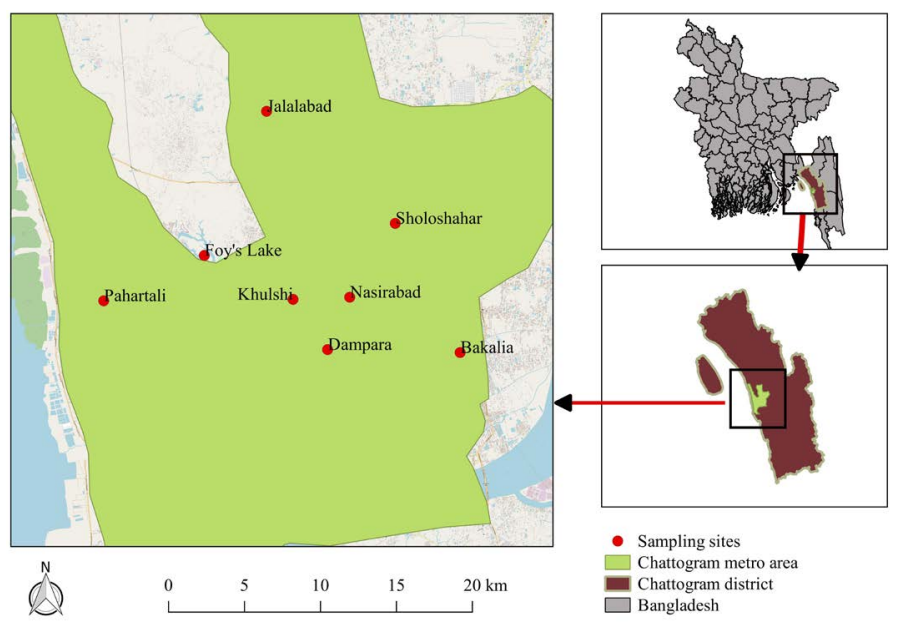

Figure 1: Sites of sampling in Chattogram metropolitan area under Chattogram district.

\section{SELECTION OF FARM AND DATA COLLECTION}

Pigeon farms and pigeons of the Chattogram metropolitan area were used as the reference population for this study. Pigeon farms and pigeons belonging to the Chattogram metropolitan areas of the Chattogram district were used as the source population for this study. A total of 100 pigeon's blood samples were collected from different parts of the Chattogram Metropolitan area conducted during the period from February to August, 2018. Different data were recorded using a validated pre-structured questionnaire through face-to-face interviews. The questionnaire contained data on type of bird, age, breed, sex, status of vaccination, previous disease status, clinical signs, duration of illness and presumptive diagnosis. Prior to the application of the questionnaire, verbal consent was taken from each farmer. During sample collection, there were four categories of clinical symptoms included in the study based on clinical signs of the pigeons (Table 1).

\section{COLLECTION OF BLOOD AND SERUM PREPARATION}

A total of $1 \mathrm{~mL}$ blood was collected from the wing vein of each pigeon in a red top vacutainer (blood collection tube) (Shirai et al., 2017). After the blood was drawn, the vacutainer was sited upright for 30-60 minutes at room temperature to allow the clot to form (Tuck et al., 2009). Then the serum was prepared by centrifugation of the vacutainer at 2000-3000 rpm (Revolutions per minute) 
for 20 minutes at room temperature $\left(25^{\circ} \mathrm{C}\right)$ (Tuck et al., 2009; Greening and Simpson, 2017). Serum sample was separated and transferred into a labeled cryovials using a pipette and stored at $-80^{\circ} \mathrm{C}$ until used (Tuck et al., 2009; Greening and Simpson, 2017).

\section{SANDWICH ENZYME-LINKED IMMUNOSORBENT ASSAY} TEST

Sandwich enzyme-linked immunosorbent assay (Sandwich-ELISA) (Catalogue number: SL0042BI; Sunlong Biotech, China) was performed to detect the concentration of $C$. psittaci antibodies (Cps-Ab) in the sera samples collected from pigeons according to the manufacturer protocol.

Among ninety-six wells in the Micro ELISA strip plate, two wells were left as negative controls, two wells as positive controls, one well was left empty as blank control and ninety-one wells were used for samples. A total volume of $50 \mu \mathrm{L}$ negative and positive controls were added to the negative and positive control wells respectively, where sample wells were filled with $40 \mu \mathrm{L}$ sample dilution buffer and $10 \mu \mathrm{L}$ serum sample. The plate was sealed with closure plate membrane and incubated at $37^{\circ} \mathrm{C}$ for 30 minutes. The concentrated buffer was diluted with distilled water. Then closure plate membrane was peeled off, aspirated and refilled with the wash solution. The wash solution was discarded after resting for 30 seconds. The procedure was then repeated for 5 times. After washing, $50 \mu \mathrm{L}$ Horseradish Peroxidase conjugate reagent was added to each well except the blank control well and incubated and washed accordingly. A total volume of $50 \mu \mathrm{L}$ chromogen solution A and chromogen solution B were added to each well to add color to the wells, which were then incubated again at $37^{\circ} \mathrm{C}$ for 15 minutes. To terminate the reaction, $50 \mu \mathrm{L}$ stop solution was added to each well and absorbance optical density (OD) was read at $450 \mathrm{~nm}$ using a Microtiter Plate Reader.

\section{INTERPRETATION OF THE RESULT}

The identification and classification of antibodies (Cps$\mathrm{Ab}$ ) of $C$. psittaci were done according to the literature of Sunlong Biotech where the average value of the positive control was $\geq 1.00$ and the average value of the negative control was $\leq 0.10$. Calculation of critical value (cut off) was performed adding 0.15 to the average value of negative control. When OD value <cut off then the sample was considered as $\mathrm{Cps}-\mathrm{Ab}$ negative. If the $\mathrm{OD}$ value $\geq \mathrm{cut}$ off then the sample was considered as $\mathrm{Cps}-\mathrm{Ab}$ positive (Sunlong Biotech, China).

\section{STATISTICAL ANALYSIS}

Field and laboratory data were entered into a Microsoft Excel 2007 spreadsheet program, checked for validity and then exported to STATA14 (Stata Crop, Lakeway Drive, College Station, Texas, USA) for data summary and analysis. Frequency was calculated by dividing the positive number of pigeons for $C$. psittaci against the number of samples tested under each of the following variables (location, age, sex, breed, duration of illness, clinical conditions). Chisquare test was performed between each of the risk factor and Chlamydia positive pigeons to get a $p$-value, where $p<$ 0.05 was considered as significant (Akter et al., 2020).

\section{RESULTS AND DISCUSSION}

\section{Overall Seroprevalence of C . PSITTACI}

A total of 100 blood samples were collected from 100 pigeons from different areas of the Chattogram metropolitan areas. Of the collected samples, ninety-one were used in this study. Due to poor sample quality nine samples were discarded. The estimated seroprevalence of $C$. psittaci was 6.6\% (6/91) in the present study.

\section{Seroprevalence of C. psittaci based on disease} PATTERN

Out of ninety-one samples, conjunctivitis and symptoms of ND were found in $20 \%$ of positive samples containing C. psittaci antibody. While $17.7 \%$ and $14.3 \%$ seropositive samples of $C$. psittaci had symptoms of ND and enteric pathogens infection, respectively and none were found to be positive for parasitic infection. It can be postulated that, pigeons highly infected by conjunctivitis and ND shows high prevalence of $C$. psittaci antibody in the sera (Figure 2).

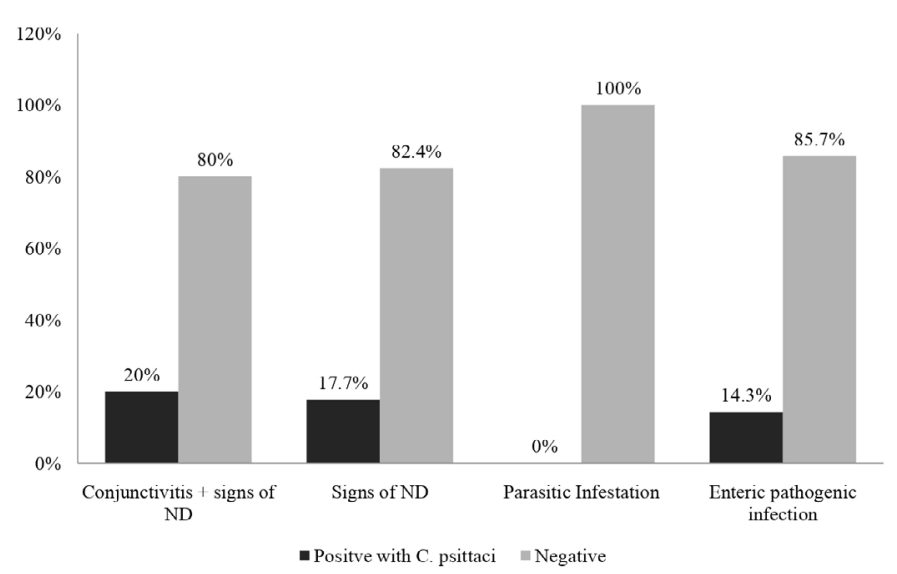

Figure 2: Percentages of positive and negative results of ELISA based on pattern of disease symptoms as recorded during this study.

\section{Seroprevalence of C. PSITTACI IN PIGEON BASED ON VARIOUS EPIDEMIOLOGICAL FACTORS}

According to the present study, the sera collected from Dampara have the highest prevalence of C. psittaci antibody (2.2\%) while Nasirabad and Pahartali have no positive samples. High prevalence of antibody (9.7\%) in 
OPEN $\odot$ ACCESS

young pigeons ( $\leq 6$ months) demonstrated that, they are highly susceptible to $C$. psittaci infection.

Chlamydia psittaci antibody was predominant in male birds (8.2\%) compared to female (3.3\%). Among five pigeon breeds studied in the survey, local pigeons (5.5\%) showed more $C$. psittaci antibody followed by King (1.1\%). The $C$. psittaci antibody was not detected in sera samples collected from remaining pigeon breeds. The present study revealed that, comparatively weak and previously sick birds were more susceptible to $C$. psittaci infection. Conjunctivitis and symptoms of ND were predominantly correlated to C. psittaci infection (20\%). Samples for serum analysis of $C$. psittaci antibody were collected during the summer samples. So, the result of the present study could not reflect the seasonal seroprevalence in pigeons.

The present study demonstrates the presence of $C$. psittaci antibodies in pigeons was $6.6 \%(6 / 91)$ in the study area, while, in China, C.psittaci antibodies were detected in 74 out of 685 sera samples (10.8\%) in pet birds in 2014 (Cong et al., 2014).However,in Switzerland, the same measurement was

Table 1: Clinical signs of cases as recorded during sample collection for this study.

\section{Clinical conditions}

Conjunctivitis and Newcastle Disease (ND) ND

Parasitic Infestation

Enteric pathogens infection

\section{Clinical signs}

Lacrimation, mucopurulent discharge from eyes, greenish diarrhea, twisted neck Twisted neck, greenish diarrhea, drowsiness

Diarrhea, inappetence, weight loss, lethargy

Watery diarrhea, loss of appetite, lethargy

Table 2: Seroprevalence of C. psittaci in pigeon based on various epidemiological factors.

\begin{tabular}{|c|c|c|c|c|c|c|}
\hline Factors & Categories & $\begin{array}{l}\text { Number of } \\
\text { sera tested }\end{array}$ & $\begin{array}{l}\text { No of positive } \\
\text { sera }\end{array}$ & $\begin{array}{l}\text { Percentage } \\
\text { (\%) }\end{array}$ & $\begin{array}{l}95 \% \text { confidence } \\
\text { interval }(\mathrm{CI})\end{array}$ & p value \\
\hline \multirow[t]{8}{*}{ Location } & Sholashahar & 8 & 0 & 0 & $0.0-0.0$ & \multirow[t]{8}{*}{0.066} \\
\hline & Dampara & 11 & 2 & 2.2 & $0.3-7.7$ & \\
\hline & Foy's lake & 3 & 1 & 1.1 & $0.0-6.0$ & \\
\hline & Jalalabad & 10 & 1 & 1.1 & $0.0-6.0$ & \\
\hline & Khulshi & 4 & 1 & 1.1 & $0.0-6.0$ & \\
\hline & Nasirabad & 36 & 0 & 0 & $0.0-0.0$ & \\
\hline & Pahartali & 13 & 0 & 0 & $0.0-0.0$ & \\
\hline & Potenga & 6 & 1 & 1.1 & $0.0-6.0$ & \\
\hline \multirow[t]{3}{*}{ Age of bird } & $<6$ months & 31 & 3 & 3.3 & $0.7-9.3$ & \multirow[t]{3}{*}{0.652} \\
\hline & $\geq 6-<12$ months & 57 & 3 & 3.3 & $0.7-9.3$ & \\
\hline & $\geq 1$ year & 3 & 0 & 0 & $0.0-0.0$ & \\
\hline \multirow[t]{2}{*}{ Sex } & Male & 61 & 5 & 5.5 & $1.8-12.4$ & \multirow[t]{2}{*}{0.379} \\
\hline & Female & 30 & 1 & 1.1 & $0.0-6.0$ & \\
\hline \multirow[t]{5}{*}{ Breed } & Giribaj & 8 & 0 & 0 & $0.0-0.0$ & \multirow[t]{5}{*}{0.705} \\
\hline & King & 6 & 1 & 1.1 & $0.0-6.0$ & \\
\hline & Local & 69 & 5 & 5.5 & $1.8-12.4$ & \\
\hline & Owl & 3 & 0 & 0 & $0.0-0.0$ & \\
\hline & Siraji & 5 & 0 & 0 & $0.0-0.0$ & \\
\hline \multirow{4}{*}{$\begin{array}{l}\text { Duration of } \\
\text { previous illness }\end{array}$} & 1 week & 13 & 1 & 1.1 & $0.0-6.0$ & \multirow[t]{4}{*}{0.057} \\
\hline & $<1$ week & 32 & 5 & 5.5 & $1.8-12.4$ & \\
\hline & 3 months & 3 & 0 & 0 & $0.0-0.0$ & \\
\hline & None & 43 & 0 & 0 & $0.0-0.0$ & \\
\hline \multirow{5}{*}{$\begin{array}{l}\text { Clinical } \\
\text { conditions }\end{array}$} & Conjunctivitis and signs of ND & 10 & 2 & 2.2 & $0.3-7.7$ & \multirow[t]{5}{*}{0.027} \\
\hline & Signs of ND & 17 & 3 & 3.3 & $0.7-9.3$ & \\
\hline & Parasitic Infestation & 11 & 0 & 0 & $0.0-0.0$ & \\
\hline & Entero pathogenic infection & 7 & 1 & 1.1 & $0.0-6.0$ & \\
\hline & None & 46 & 0 & 0 & $0.0-0.0$ & \\
\hline
\end{tabular}


$8.4 \%$ in feral pigeons (Geigenfeind et al., 2012). Such variations in seroprevalence of $C$. psittaci in different areas are likely due to differences in animal welfare, the number of birds tested, husbandry practices, geographical conditions and stage of infection as well as the specificity and sensitivity of the detection methods (Cong et al., 2014; Zhang et al., 2015). Moreover, sometimes problems arise due to sera containing low levels of antibody that lead to difficulties in finding and defining of correct cut-off levels of antibody against C. psittaci (Gerbermann et al., 1990; Andersen, 2000).

Potential risk factors that could be associated with the occurrence of $C$. psittaci infections in pigeons were evaluated in the current study. Moreover, previous studies have demonstrated that the age of the bird presented the potential risk factor for $C$. psittaci infection (Cong et al., 2014; Zhang et al., 2015). In the present study, risk factor analysis also showed that age appeared to be the main risk factor associated with Chlamydia infection. In the present study, the highest prevalence of antibody was reported in juveniles $(<6$-month-age $=9.7 \%)$ compared to older birds $(\geq 6$-month-old $=5.2 \%)$. This finding was consistent with a recent study in pet parrots in China (Zhang et al., 2015), which was most likely due to juveniles having comparatively weak immune systems (more susceptible) than adult birds (Zhang et al., 2015). Another study has reported the seroprevalence of $C$. psittaci infections in adult birds (12.4\%) as higher than that of young birds (4.8\%) (Cong et al., 2014). Whether the difference of C. psittaci seroprevalence among different age groups of pigeons is a result of naive immunity or repeated exposures to Chlamydia spp. should be further studied.

Furthermore, seroprevalence of $C$.psittaciin male pigeon was higher than female pigeons in our study. The finding agreed with (Stokes et al., 2020). This may be due to susceptibility of males to C. psittaci infection being higher than that of females (Zuk and McKean, 1996). Alternatively, males have a longer-lasting antibody response than females and their antibodies would remain elevated for a longer time in blood level (Zuk and McKean, 1996; Wilson et al., 2013; Stokes et al., 2020).

Stokes et al. (2020) agreed with our finding that there is a significant difference in seroprevalence of $C$. psittaci among sites of sample collection (Stokes et al., 2020). Moreover, we found higher seroprevalence of $C$. psittaci in local pigeon breed than other breeds like Giribaj, King and Siraji etc. Stokes et al. (2020) also found high prevalence in case of local wild psittacine birds in Australia (Stokes et al., 2020). Free ranging local pigeons are highly infected by $C$. psittaci when compared to fencing pigeons as they get a great contact with the environment which increases the possible of contamination with different avian diseases.
In the current study, birds positive with C. psittaci antibody were sampled during the summer. Therefore, the result could not reflect the seasonal seroprevalence in pigeons and requires further study. However, other studies have reported that no significant association between the occurrence of C. psittaci infections and the season exists (Madani and Peighambari, 2013; Zhang et al., 2015).

It is worth mentioning that, samples were collected only from different parts of the Chattogram Metropolitan area and the study was conducted during the period of February to August, 2018. Therefore, the prevalence reported here might not reflect the rate of actual $C$. psittaci infection in Bangladesh. However, our results highlighted the zoonotic potential of $C$. psittaci within the country and provided some useful baseline information for future studies.

This study suggests that feral pigeons could be infected with C. psittaci and thus presents a health risk to both the public and individual pigeon owners. Despite the low level of infection rate detected in feral pigeons by antibody titer, the risk of disease transmission can never be ruled out, since there is an increased likelihood of close contact between feral pigeons and humans in city environments.

\section{CONCLUSIONS AND RECOMMENDATIONS}

From the present study, it can be concluded that $C$. psittaci is prevalent in domestic pigeons in the study area, which may pose potential threat to human health. Disseminating effective prevention and control measures such as daily removal of feces and disinfection of cages are suggested for maintaining hygienic conditions and to reduce the risk of C. psittaci infection among psittacine birds. This will also reduce the risk of infection among humans in contact with these birds. However, this is a complex issue that requires careful planning and should involve the community, government and animal protection societies as well as scientists. Furthermore, limitations of the study were lack of few farm associated risk factors data in the primary questionnaire and small sample size.

\section{ACKNOWLEDGMENTS}

The authors also acknowledge the Advance Study and Research, Chattogram Veterinary and Animal Sciences University, Bangladesh, and the National Science and Technology Fellowship under the Ministry of Science and Technology, The Peoples Republic of Bangladesh, for funding the research work. The authors thankful to Dr. Md. Shafiullah Parvej, Gono Bishwabidyalay, Dhaka, Bangladesh and Dr. Nasir Uddin, PhD Fellow, Chinese Academy of Sciences for their critical review of the 
manuscript.

\section{NOVELTY STATEMENT}

The novelty of this study is quite significant in Bangladesh. Though a lot of people especially the young generation are now engaged in pigeon farming in Bangladesh, they have little knowledge about the zoonotic importance of Chlamydia psittaci. As this study is the first known evidence in Bangladesh, it will help to develop awareness among different stakeholders like pigeon farmers, veterinarians, laboratory and wildlife workers as well as animal welfare activists. This study also enlightens researchers by highlighting baseline information for further research in this field.

\section{AUTHOR'S CONTRIBUTION}

All the authors have contributed in terms of giving their technical expertise to give a tenable shape to this manuscript.

\section{CONFLICT OF INTEREST}

The authors have declared no conflict of interest.

\section{ETHICS APPROVAL STATEMENT}

This research work has been done with approval by the appropriate ethical committee "Advance Study and Research" of Chattogram Veterinary and Animal Sciences University, Bangladesh. We did not harm or sacrifice any animals in the study.

\section{REFERENCES}

-Akter S, Rahman MM, Sayeed MA, Islam MN, Hossain D, Hoque MA, Koop G (2020). Prevalence, aetiology and risk factors of subclinical mastitis in goats in Bangladesh. Small Rumin. Res., 184: 106046. https://doi.org/10.1016/j. smallrumres.2020.106046

-Alam MA, Ali MS, Das NG, Rahman MM (2014). Present status of rearing backyard poultry in selected areas of Mymensingh district. Bangladesh J. Anim. Sci., 43: 30-37. https://doi.org/10.3329/bjas.v43i1.19382

-Andersen AA (2000). Avian chlamydiosis. In OIE Standards Commission (Ed.). In: Manual of standards for diagnostic tests and vaccines, $4^{\text {th }}$ editio. Paris: Office International des Epizooties, pp. 679-90.

- Asaduzzaman M, Mahiuddin M, Howlider MAR, Hossain MM, Yeasmin T (2009). Pigeon farming in Gouripur upazilla of Mymensingh district. Bangladesh J. Anim. Sci., 38: 142-150. https://doi.org/10.3329/bjas.v38i1-2.9923

-Balsamo G, Maxted AM, Midla JW, Murphy JM, Wohrle R, Edling TM, Fish PH, Flammer K, Hyde D, Kutty PK (2017). Compendium of measures to control Chlamydia psittaci infection among humans (psittacosis) and pet birds (avian chlamydiosis), 2017. J. Avian Med. Surg., 31: 262282. https://doi.org/10.1647/217-265
- CDC (Centers for Disease Control and Prevention) (2016). Summary of notifiable infectious diseases and conditions United States, 2014. MMWR Morb Mort Wkly Rep, 63: $1-152$.

- Cong W, Huang SY, Zhang XX, Zhou DH, Xu MJ, Zhao Q, Qian AD, Zhu XQ (2014). Chlamydia psittaci exposure in pet birds. J. Med. Microbiol., 63: 578-581. https://doi. org/10.1099/jmm.0.070003-0

- Cooper JE (1997). Possible health hazards from birds in the rural environment. Trans. R. Soc. Trop. Med. Hyg., 91: 366367. https://doi.org/10.1016/S0035-9203(97)90114-0

-Doosti A, Arshi A (2011). Determination of the Prevalence of Chlamydia psittaci by PCR in Iranian Pigeons. Int. J. Biol., 3: 79. https://doi.org/10.5539/ijb.v3n4p79

-Eidson M (2002). Psittacosis/avian chlamydiosis. J. Am. Vet. Med. Assoc., 221: 1710-1712. https://doi.org/10.2460/ javma.2002.221.1710

-Entrican G, Wheelhouse NM (2006). Immunity in the female sheep reproductive tract. Vet. Res., 37: 295-309. https://doi. org/10.1051/vetres:2006002

-Geigenfeind I, Vanrompay D, Haag-Wackernagel D (2012). Prevalence of Chlamydia psittaci in the feral pigeon population of Basel, Switzerland. J. Med. Microbiol., 61: 261-265. https://doi.org/10.1099/jmm.0.034025-0

- Gerbermann H,JakobyJR, Kösters J (1990).Chlamydienbefunde aus einer größeren Greifvogelhaltung. J. Vet. Med. Ser. B., 37: 739-748. https://doi.org/10.1111/j.1439-0450.1990. tb01122.x

- Goellner S, Schubert E, Liebler-Tenorio E, Hotzel H, Saluz HP, Sachse K (2006). Transcriptional response patterns of Chlamydophila psittaci in different in vitro models of persistent infection. Infect. Immun., 74: 4801-4808. https:// doi.org/10.1128/IAI.01487-05

- Gofur MR (2020). Textbook of avian anatomy, $1^{\text {st }}$ editio. Uttoran Offset Printing Press, Rajshahi, Bangladesh.

- Greening DW, Simpson RJ (2017). Serum/Plasma Proteomics. Springer. https://doi.org/10.1007/978-1-4939-7057-5

-Haag-Wackernagel D (2006). Human diseases caused by feral pigeons. Adv. Vertebr. Pest Manage., 4: 31-58.

-Heddema ER, Ter Sluis S, Buys JA, Vandenbroucke-Grauls CMJE, van Wijnen JH, Visser CE (2006). Prevalence of Chlamydophila psittaci in fecal droppings from feral pigeons in Amsterdam, The Netherlands. Appl. Environ. Microbiol., 72: 4423-4425. https://doi.org/10.1128/AEM.02662-05

-Johnston WB, Eidson M, Smith KA, Stobierski MG (2000). Compendium of measures to control Chlamydia psittaci infection among humans (psittacosis) and pet birds (avian chlamydiosis), 2000. Morb. Mortal. Wkly. Rep. Recomm. Rep., pp. 1-17.

-Longbottom D, Coulter LJ (2003). Animal chlamydioses and zoonotic implications. J. Comp. Pathol., 128: 217-244. https://doi.org/10.1053/jcpa.2002.0629

- Madani SA, Peighambari SM (2013). PCR-based diagnosis, molecular characterization and detection of atypical strains of avian Chlamydia psittaci in companion and wild birds. Avian Pathol., 42: 38-44. https://doi.org/10.1080/0307945 7.2012 .757288

- Meyer KF (1941). Pigeons and Barn Yard Fowls as Possible Sources of Human Psittacosis or Ornithosis. Schweiz. Med. Wochenschr., 71: 1377-1379.

-Morita Y, Arai M, Nomura O, Maruyama S, Katsube Y (1994). Avian tuberculosis which occurred in an imported pigeon and pathogenicity of the isolates. J. Vet. Med. Sci., 56: 585- 
587. https://doi.org/10.1292/jvms.56.585

- Ni X, Qin S, Lou Z, Ning H, Sun X (2015). Seroprevalence and risk factors of Chlamydia infection in domestic rabbits (Oryctolagus cuniculus) in China. Biomed Res. Int., 2015. https://doi.org/10.1155/2015/460473

- Pannekoek Y, Visser C, Duim B, Heddema ER (2009). Chlamydophila psittaci infections in The Netherlands. Drugs of Today (Barcelona, Spain: 1998), 45: 151-157.

- Parvez MNH, Islam MR, Sarder MJU, Gofur MR (2020). Postnatal development and egg morphometry of different breeds of pigeon available at northern Barind tract in Bangladesh. Asian J. Med. Biol. Res., 6: 594-598. https:// doi.org/10.3329/ajmbr.v6i3.49813

-Rohde G, Straube E, Essig A, Reinhold P, Sachse K (2010). Chlamydial zoonoses. Dtsch. Arztebl. Int., 107: 174. https:// doi.org/10.3238/arztebl.2010.0174

- Shirai T, Furusawa H, Furukawa A, Ishige Y, Uchida K, Miyazaki Y, Eishi Y, Inase N (2017). Protein antigen of bird-related hypersensitivity pneumonitis in pigeon serum and dropping. Respir. Res., 18: 1-9. https://doi.org/10.1186/s12931-0170555-4

- Smith KA, Bradley KK, Stobierski MG, Tengelsen LA (2005). Compendium of measures to control Chlamydophila psittaci (formerly Chlamydia psittaci) infection among humans (psittacosis) and pet birds, 2005. J. Am. Vet. Med. Assoc., 226: 532-539. https://doi.org/10.2460/javma.2005.226.532

-Stokes HS, Martens JM, Walder K, Segal Y, Berg ML, Bennett ATD (2020). Species, sex and geographic variation in Chlamydial prevalence in abundant wild Australian parrots. Sci. Rep., 10: 1-13. https://doi.org/10.1038/s41598-02077500-5

-TuckMK, Chan DW, Chia D, Godwin AK, Grizzle WE, Krueger
KE, Rom W, Sanda M, Sorbara L, Stass S (2009). Standard operating procedures for serum and plasma collection: early detection research network consensus statement standard operating procedure integration working group. J. Proteome Res., 8: 113-117. https://doi.org/10.1021/pr800545q

-Vanrompay D, Harkinezhad T, Van de Walle M, Beeckman D, Van Droogenbroeck C, Verminnen K, Leten R, Martel A, Cauwerts K (2007). Chlamydophila psittaci transmission from pet birds to humans. Emerg. Infect. Dis., 13: 1108. https://doi.org/10.3201/eid1307.070074

-Verminnen K, Vanrompay D (2009). Chlamydophila psittaci infections in turkeys: overview of economic and zoonotic importance and vaccine development. Drugs of Today (Barcelona, Spain: 1998), 45: 147-150.

-Wilson HM, Hall JS, Flint PL, Franson JC, Ely CR, Schmutz JA, Samuel MD (2013). High seroprevalence of antibodies to avian influenza viruses among wild waterfowl in Alaska: implications for surveillance. PLoS One, 8: e58308. https:// doi.org/10.1371/journal.pone.0058308

-Wu S-M, Huang S-Y, Xu M-J, Zhou D-H, Song H-Q, Zhu $\mathrm{X}-\mathrm{Q}$ (2013). Chlamydia felis exposure in companion dogs and cats in Lanzhou, China: a public health concern. BMC Vet. Res., 9: 1-5. https://doi.org/10.1186/1746-6148-9-104

-Zhang N-Z, Zhang X-X, Zhou D-H, Huang S-Y, Tian W-P, Yang Y-C, Zhao Q, Zhu X-Q (2015). Seroprevalence and genotype of Chlamydia in pet parrots in China. Epidemiol. Infect., 143: 55-61. https://doi.org/10.1017/ S0950268814000363

-Zuk M, McKean KA (1996). Sex differences in parasite infections: Patterns and processes. Int.J. Parasitol., 26: 10091024. https://doi.org/10.1016/S0020-7519(96)80001-4 